\title{
CORRECTION
}

M. Gonzalez

\section{Correction to: Alignment dynamics of diffusive scalar gradient in a two-dimensional model flow}

Published online: 31 May 2018

(c) Springer-Verlag GmbH Germany, part of Springer Nature 2018

\section{Correction to: Theor. Comput. Fluid Dyn.}

https://doi.org/10.1007/s00162-018-0459-z

In the original publication, the inline equations under the section '5.1.1 Prevailing strain' are incorrect. They have been identified as follows.

$$
\begin{aligned}
S_{e q} & =\operatorname{sgn}\left[\left(\theta-\theta_{e q}\right) \cdot D \theta / D t\right] \text { has to be read: } S_{e q}=\operatorname{sgn}\left\{\theta-\theta_{e q}\right\} \cdot D \theta / D t \\
S_{c} & =\operatorname{sgn}\left[\left(\theta-\theta_{c}\right) \cdot D \theta / D t\right] \text { has to be read: } S_{c}=\operatorname{sgn}\left\{\theta-\theta_{c}\right\} \cdot D \theta / D t
\end{aligned}
$$

$A_{e q}^{-}=\int_{-1}^{0} S_{e q} d S_{e q}$ and $A_{c}^{-}=\int_{-1}^{0} S_{c} d S_{c}$ has to be read: $A_{e q}^{-}=\int_{-1}^{0} P\left(S_{e q}\right) d S_{e q}$ and $A_{c}^{-}=\int_{-1}^{0} P\left(S_{c}\right) d S_{c}$, where $P\left(S_{e q}\right)$ and $P\left(S_{c}\right)$ are, respectively, the p.d.f's of $S_{e q}$, and of $S_{c}$

The original article can be found online at https://doi.org/10.1007/s00162-018-0459-z. 